\title{
Study on environmental path co-efficient in dahlia
}

\author{
H. M. Singh* and U. S. Mishra ${ }^{1}$ \\ National Horticultural Research and Development Foundation, INDORE (M.P.) INDIA \\ (Email : hmsingh1983@gmail.com)
}

\begin{abstract}
Dahlia is an importance bulbous flower crop which has position to increase economic earning of grower. Forty varieties were grown and studied for environmental path correlation of traits at C.S. Azad University of Agriculture and Technology, Kanpur, during 2011-12 and 2012-13. Vegetative and reproductive character parameters were found to have considerable relationship which also indicated the scope for making improvement in dahlia. Plant height and maximum number of flower per head revealed the sustainable magnitude for crop improvement in dahlia crop.
\end{abstract}

Key Words : Species, Varieties, Germplasm, Dahlia, Path

View Point Article : Singh, H.M. and Mishra, U. S. (2018). Study on environmental path co-efficient in dahlia. Internat. J. agric. Sci., 14 (1) : 192-195, DOI:10.15740/HAS/IJAS/14.1/192-195.

Article History : Received : 28.10.2017; Revised : 30.11.2017; Accepted : 13.12.2017

\footnotetext{
* Author for correspondence:

${ }^{1}$ Mahatma Gandhi Chitrakoot Gramodaya Vishwavidyalaya, Chitrakoot, SATNA (M.P.) INDIA
} 